\title{
Challenges to parent nutrition education: a qualitative study of parents of urban children attending low-income schools
}

\author{
Wendelin Slusser ${ }^{1,2, *}+$, Michael Prelip ${ }^{1}$, Janni Kinsler ${ }^{1}$, Jennifer Toller Erausquin ${ }^{3}$, \\ Chan Thai ${ }^{4}$ and Charlotte Neumann ${ }^{1}$ \\ 'Department of Community Health Sciences, School of Public Health, University of California at Los Angeles, \\ Los Angeles, CA, USA: ${ }^{2}$ Department of Pediatrics, Mattel Children's Hospital, School of Medicine, University of \\ California at Los Angeles, Los Angeles, CA, USA: ${ }^{3}$ Duke Global Health Institute, Duke University, Durham, NC, \\ USA: ${ }^{4}$ Department of Communication, University of California at Santa Barbara, Santa Barbara, CA, USA
}

Submitted 26 July 2010: Accepted 20 February 2011: First published online 11 April 2011

\begin{abstract}
Objective: The present study was undertaken to learn more about parents' (i) knowledge regarding healthy foods, factors associated with food purchasing and preparation, and current nutrition education resources, (ii) barriers to and promoters for establishing healthy eating habits for children and families, and (iii) interest in participating in nutrition interventions.

Design: Focus group interviews were conducted with parents of low-income children from the Los Angeles Unified School District (LAUSD).

Setting: LAUSD Title 1 elementary schools where $50 \%$ or more of students are eligible for free/reduced-price meals.

Subjects: Sixty-four parents (93\% female; 84\% Hispanic/Latino) of elementaryschool students.

Results: The most common barriers to eating healthy foods were cost, difficulty in getting children to eat healthier foods and easy access to fast food. Parents had a basic knowledge about what foods are healthy and received most of their nutrition education through the media. Parents expressed a desire for nutrition classes and almost all of them said they would attend a nutrition programme at their child's school. Topic areas of interest included what to purchase, how to cook healthier foods, how to encourage their children to eat healthier and how to read food labels. Parents also requested classes that engage the whole family, especially fathers.

Conclusions: Parents in our study were interested in participating in nutrition education programmes. The information from these focus groups was used to design a parent nutrition education programme especially designed to respond to the needs of the LAUSD parents, the majority of whom are low-income and Hispanic/Latino.
\end{abstract}

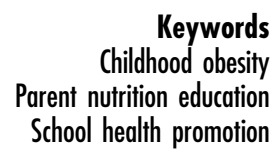

Childhood obesity is a worldwide problem and has accelerated in recent years, especially in the USA. In addition to genetics and a complex web of sociocultural, economic, environmental, educational and psychosocial factors, parental influence on children's eating patterns and food intake is an important predictor of the development of childhood obesity ${ }^{(1-3)}$. The Institute of Medicine recommends parents promote healthful eating behaviours and regular physical activity for their children, emphasizing the importance of family involvement in shaping children's dietary and activity practices ${ }^{(4)}$. Targeting parents to improve children's dietary and physical

$\uparrow$ Correspondence address: UCLA Schools of Public Health and Medicine, Department of Community Health Sciences, 10990 Wilshire Blvd Suite 900, Los Angeles, CA 90024, USA. activity behaviours is necessary for prevention and treatment of children who are overweight and is considered a feasible strategy, given that parents are mostly responsible for food choices and can influence the eating patterns and food intake of their children, especially during childhood $^{(4,5)}$. Parental influence is thought to operate primarily through modelling, providing opportunities for children to observe their parents eating healthy foods or engaging in physical activity, serving appropriate portion sizes for age and setting limits for dietary intake ${ }^{(1,6-10)}$.

In order for parents to impact their children's food behaviours and attitudes, parents need among many tools the knowledge about healthy foods, resources to support them in their nutrition education and the skills to purchase healthy foods and prepare them in a healthy manner ${ }^{(11,12)}$. In previous qualitative work, parents expressed an interest 
and desire to learn about nutrition and in addition wanted to know the 'how' for changing unhealthy nutrition behaviours $^{(12)}$. Nutrition education alone has been found to accomplish limited positive changes in parent nutrition behaviours. For example, a systematic review of interventions at decreasing obesity in children younger than 2 years old reported nutrition education programmes had limited impact on improving dietary intake and parental attitudes and knowledge about nutrition for children, and none of the interventions improved child weight status ${ }^{(13)}$.

Indeed, parent education alone is not sufficient to promote healthy eating behaviours. The desire or motivation to follow the US Department of Agriculture's (USDA) dietary guidelines about healthy food choices and the opportunities (access and availability) to eat a healthy diet are influenced by a number of factors that can act as barriers or facilitators in promoting healthy food choices; these factors include socio-economic status and lack of access to healthy and affordable foods ${ }^{(11)}$. Among the most common barriers described in the literature are family schedules, lack of money to purchase healthy food, lack of time to prepare healthy meals, the accessibility and desirability of unhealthy foods, and lack of knowledge about the nutrient content of unhealthy fast foods ${ }^{(7,11,14)}$. One study found parents blamed their children for their unhealthy behaviour, making references to poor appetites, picky eating, preferences for junk food and fast food, and resistance to parental attempts to encourage health behaviours ${ }^{(6)}$.

In addition to barriers for parents in promoting healthy food choices, there are challenges in stimulating involvement among parents in nutrition education programmes $^{(15-17)}$. For example, work by Baranowski et al. highlights how impacting healthy food intake at home is challenging and developing effective interventions targeting parents is difficult ${ }^{(17)}$. Hart et al. also found parents were not receptive to interventions aimed at encouraging dietary behaviour change at a family or personal level ${ }^{(11)}$. In general, engaging low-income minority parents with young children in preventive parenting interventions has been found to be challenging because of competing time commitments and priorities, unstable schedules and lack of transportation ${ }^{(18)}$.

In 2006, Network for a Healthy California-Los Angeles Unified School District (referred to hereafter as the Network') decided to initiate a series of activities to assess the feasibility of creating intervention components targeting the parents of low-income children. As part of these formative research efforts, the Public Health Nutrition Friendly Team of the University of California at Los Angeles (UCLA) conducted a series of focus group interviews with parents of children from Los Angeles Unified School District (LAUSD) Title 1 schools to learn more specifically about LAUSD parents': (i) knowledge regarding healthy foods, factors associated with food purchasing and preparation, and current nutrition education resources; (ii) barriers to and promoters for establishing healthy eating habits for children and families; and (iii) interest in participating in nutrition interventions. The UCLA School of Public Health Nutrition Friendly Schools and Community Group has been working with the Network on nutrition education programming for many years. Most of the Network's direct efforts have focused on lowincome children. Focusing on the low-income and racial/ ethnic minority populations to answer these questions is of particular interest given that the prevalence of obesity among US adults and children is much higher among racial/ethnic minority populations such as Hispanics/ Latinos and African-American compared with Caucasians. Individuals of low socio-economic status, particularly women and children within minority populations, appear to be particularly affected by obesity ${ }^{(19,20)}$.

\section{Methods}

\section{Study context}

LAUSD is the second largest school district in the USA, and has the second largest federally funded food programme and the largest federally funded breakfast programme in the country. Over $70 \%$ of the student population in the LAUSD is Hispanic. Forty-two per cent of elementary- and secondary-school children in the District are obese or overweight. Prevalence of obesity varies by race/ethnicity, with Hispanics/Latinos (27\%) and African Americans (22\%) having a higher prevalence than whites $(13 \%)$ and Asians $(12 \%)^{(21,22)}$. The percentage of overweight schoolchildren has generally been increasing at a faster rate at LAUSD than at other school districts in Los Angeles County ${ }^{(23)}$.

In 2000, the Network was launched in response to the growing childhood obesity epidemic ${ }^{(21,24-26)}$. The purpose of the Network was to coordinate the delivery of nutrition education messages to the low-income population eligible for the USDA Supplemental Nutrition Assistance Program (SNAP) and to navigate and understand the SNAP programme ${ }^{(27)}$. The Network has grown since the year 2000, and now reaches 233000 LAUSD students attending Title 1 schools through classroom and outreach activities, and more than 9300 teachers, school nurses and other school personnel. The majority of the programme's resources are focused on educating the children through their teachers during the regular school day. In addition, the Network was providing limited nutrition education for parents at the time of the present study by offering one workshop per year and a few presentations focused on basic nutrition. Through this prior work, and recommendations from the LAUSD programme advisory board and schools participating in the Network, we embarked on developing a more extensive programme to engage and educate parents within the district on the importance of optimal nutrition and physical activity. 


\section{Sample}

Schools

Schools were eligible for the study if they were Network schools (i.e. Title 1 elementary schools where $50 \%$ or more of their students were eligible for free/reduced-price meals) and received funding from the USDA. The Network provided the UCLA Nutrition Friendly Schools and Communities Group research team with a list of thirteen participating Network schools that were historically open to participating in Network programmes and might be receptive to holding a focus group interview for parents. An introductory letter was sent to the principal of each elementary school on the list to inform him or her of the purpose of the study and request permission to recruit parents and conduct focus group interviews at their school. It was made clear to the principals that participation was voluntary and no negative outcomes would come to them or their school for not participating. Interested schools were asked to contact UCLA. Approximately one week after the introductory letters were sent, follow-up telephone calls were made to the principals if they did not respond. A total of five of the thirteen schools agreed to participate in the study. The participating schools were dispersed geographically throughout the District. The schools ranged in size and calendar type from 389 students on a traditional calendar to 1108 students on a year-round, four-track calendar. All five schools had a high percentage of students receiving free/reduced-price meals ranging from $81.9 \%$ of the student population to $94.0 \%$. Most of the schools had a predominantly Hispanic/Latino student population; see Table 1 for school characteristics. A date and time for the focus group(s) was arranged with the principal at each school. When possible, they were arranged prior to or after an already scheduled parent meeting.

\section{Parents}

Parents were eligible for the study if they were a parent of a child in a Network school. At the selected schools with principal permission, parent recruitment flyers in English and Spanish were sent home with all students. The recruitment flyers detailed the purpose of the study and the focus $\operatorname{group}(\mathrm{s})$, the date, time and location of the focus group(s), incentives for participating and instructions for enrolling. Additionally, these flyers were posted in parent centres. Parents were asked to telephone UCLA research staff to enrol in the focus groups and indicate which language they preferred (English or Spanish). Reminder telephone calls were made to all enrolled parents the day before the focus group.

The study was approved by the LAUSD Program Evaluation and Research Branch and the UCLA Institutional Review Board.

\section{Procedures}

Nine focus groups were held with sixty-four parents of students from LAUSD elementary schools. Two focus groups were conducted in English (eight individuals per group) and seven focus groups were conducted in Spanish (six to eight individuals per group). A brief questionnaire lasting approximately $10-15 \mathrm{~min}$ was administered to parents prior to the focus group to determine their demographics and to assess their current and past use of the Network nutrition programmes. The UCLA School of Public Health research team collaborated with the Network to develop the questions for both the focus group interview guide and questionnaire, which were guided by the literature, research objectives, topics covered in previous nutrition workshops, investigators' experience with this topic and population, and other topics that could be used for programme development. Focus groups were conducted in either English or Spanish by one bilingual (English-Spanish) facilitator from UCLA who had extensive experience working with the target population of lowincome parents. The focus group facilitator was a doctoral student and was trained by a doctoral-level project manager who provided one-on-one training regarding the focus group research goals, protocol and focus group interview guide. This particular doctoral student had prior experience both in moderation of focus groups and working with the population of interest. In addition to the trained doctoral student moderating the focus groups, the project manager attended all focus groups and assumed the role of 'note taker'. Both English and Spanish versions of the questionnaire were available. Semi-structured interviews were loosely guided by the Health Belief Model including general predisposing, enabling and reinforcing factors associated with good dietary practices ${ }^{(28)}$.

\section{Focus group interviews}

Parents participated in either an English- or Spanish-language focus group discussion lasting approximately $45 \mathrm{~min}$.

Table 1 Characteristics of participating schools: Title 1 elementary schools, Los Angeles Unified School District, Los Angeles, California, USA

\begin{tabular}{lccccrr}
\hline & $\begin{array}{c}\text { No. of } \\
\text { students }\end{array}$ & $\begin{array}{c}\text { Free/reduced- } \\
\text { price meals (\%) }\end{array}$ & $\begin{array}{c}\text { Hispanic/Latino } \\
(\%)\end{array}$ & $\begin{array}{c}\text { African } \\
\text { American (\%) }\end{array}$ & $\begin{array}{c}\text { Asian/Pacific } \\
\text { White (\%) }\end{array}$ & $\begin{array}{c}\text { American Indian/ } \\
\text { Alaska Native (\%) }\end{array}$ \\
\hline School 1 & 815 & 94 & 90 & 2 & 3 & 5 \\
School 2 & 992 & 89 & 68 & 7 & $<1$ & $<$ \\
School 3 & 1089 & 86 & 99 & 4 & $<1$ & 3 \\
School 4 & 1108 & 91 & 87 & 66 & 3 & $<$ \\
School 5 & 389 & 82 & 26 & 41 & 4 \\
\hline
\end{tabular}


A semi-structured guide was used to explore topics related to learning, more specifically about parents': (i) knowledge regarding healthy foods, factors associated with food purchasing and preparation, and current nutrition education resources; (ii) barriers to and promoters for establishing healthy eating habits for children and families; and (iii) interest in participating in nutrition interventions. The focus group facilitator probed for more information in order to clarify points made on certain topics and to get participants to expand on their responses to topics or questions. Focus groups were recorded and transcribed verbatim, with the Spanish interviews translated into English.

\section{Data analysis}

Univariate analyses were used to assess demographic characteristics and parent involvement in the educational activities of the Network.

During the focus group transcription process, participants were not identified by name to ensure their privacy. To increase inter-rater reliability, three reviewers independently reviewed the data and identified recurrent themes and selected comments supporting each theme. The three coders were faculty members at the UCLA School of Public Health with extensive research background in nutrition and paediatrics. Lists of recurrent themes were compared across reviewers and common themes were identified. Under the three objectives, there were two major themes that emerged across all focus groups and minor themes or responses that were seen in two or three of the groups but not across all nine. Based on the three reviewers, the two major themes are described below as well as a list of most relevant comments best supporting these themes and the minor themes organized under the three objectives.

Analysis continued as an iterative process through discussions and refining of the major themes using grounded theory. Grounded theory focuses on generating theory from qualitative data that will be relevant to one's own research, in contrast to beginning with a theory and then using the data to verify it ${ }^{(29)}$.

\section{Results}

\section{Sample}

Almost all of the participants were female (93.2\%) and identified as Hispanic/Latino $(84.7 \%)$. Mean age was 38.4 years. The majority $(75 \cdot 0 \%)$ of participants completed the questionnaire in Spanish. All parents ( $n$ 64) who participated in the focus groups completed the questionnaire; see Table 2 for participant characteristics.

Just over half $(51.7 \%)$ of the parents indicated they had attended a parent nutrition programme or meeting at their child's school. The percentage of parents who participated in the different nutrition workshops is presented in Table 3. Parents mostly attended workshops on nutrition
Table 2 Demographic characteristics of participating parents $(n 64)$, Los Angeles Unified School District, Los Angeles, California, USA

\begin{tabular}{lcr}
\hline Demographic characteristic & $n$ & $\%$ \\
\hline Gender & & \\
$\quad$ Male & 4 & 7 \\
Female & 60 & 93 \\
Race/ethnicity & 54 & 84 \\
$\quad$ Hispanic/Latino & 3 & 5 \\
African American & 1 & 2 \\
Asian/Pacific Islander & 1 & 2 \\
American Indian/Alaska Native & 5 & 7 \\
Other & $38 \cdot 4$ & \\
Mean age (years) & & \\
Language & 16 & 25 \\
English & 48 & 75 \\
Spanish & & \\
\hline
\end{tabular}

Table 3 Topic of parent nutrition programme attended ( $n$ 30)

\begin{tabular}{lc}
\hline What was the programme or meeting about? & $\%$ Yes $^{*}$ \\
\hline Nutrition education & $86 \cdot 7$ \\
Healthy cooking & $56 \cdot 7$ \\
Your child's health & $46 \cdot 7$ \\
Food stamps & $20 \cdot 0$ \\
\hline
\end{tabular}

${ }^{*}$ Results add up to greater than $100 \%$ because participants were able to select more than one response.

education and healthy cooking. Almost all $(90 \cdot 6 \%)$ of the parents indicated they would attend a programme or meeting about nutrition or physical activity at their child's school.

\section{Focus group interviews}

Two major themes were identified during the focus groups. The first was the balance of the pluses and minuses determining the decisions on healthy eating. For instance, families weighed the barriers to healthy eating such as cost, child's taste/preferences and time against the knowledge of what is healthy eating and the child's food preferences for healthy foods when making decisions about food purchasing and food preparation. The second theme was the topic of the child and family and its importance not only in motivating parents in making healthy choices for the health of the family, but also in including as many of the family decision makers in nutrition education efforts. These two major themes and the additional minor themes are described below under the three objectives for the study.

Objective 1: learning more about parents' knowledge regarding bealthy foods, factors associated with food purchasing and preparation, and current nutrition education resources

Basic nutrition knowledge helped guide parents in food purchasing. The majority of parents reported a basic knowledge about what is healthy, identifying all of the food groups and in particular fruits and vegetables, beans, pita bread, low sodium, low-fat milk, low saturated fat, natural foods and how foods are prepared. Many participants 
noted the method of cooking as what makes a food healthy (roasting, baking, broiling or boiling). The major theme of balancing healthy with less healthy options was expressed related to food preparation:

... when I cook something that I know has a lot of grease, I make a salad on the side with a lot of lettuce, cucumber.

Parents also had a basic knowledge of the fact children need smaller portion sizes than adults:

... if I give him a little bit of a sandwich, we can say, I give him the half, and about two slices of fruit and one carrot $\ldots$ and I prefer him to ask me for more than for him to tell me 'No, it's too much, I'm not eating.'

Some parents did state, however, they didn't know what healthier options were and others stated they didn't know how to make food healthier.

Parents identified what factors determined what foods they would buy at the grocery store and how they prepared their meals. These factors often reflected how their nutrition knowledge played an important part in their decisions of what foods to buy. Furthermore, they considered the health of the child and family when purchasing the food, sometimes choosing foods they considered healthier even if it was more expensive. Quality of food, freshness and foods known to be healthy were identified as factors in purchasing foods. When purchasing and preparing foods, parents reported trying to make healthier choices and substitutions. Many parents also thought about what the child might like to eat in regard to healthy foods and would even buy the more expensive vegetable if the child wanted to eat it. While cost influenced purchasing, parents tried to balance quality and cost.

Less frequently mentioned factors influencing foodpurchasing decisions were limited time, limited room to store healthy food items, living in a community with a lack of markets that sell healthy foods, and not knowing how to read a food label. The barriers of time and lack of availability and accessibility were also identified in the sub-themes for barriers to healthy eating.

Parents reported their sources of nutrition education were multiple, suggesting multiple opportunities to reach parents. Parents indicated they were self-taught although they were open to classes, especially if they included other family members, reflecting one of the major themes of considering the family as an important factor in healthy nutrition in this population. The participants learned about nutrition through reading and various media including television (TV), radio, newspapers and magazines. Relatives, physicians and food markets were also identified as sources of nutrition education. For example, parents reported learning about nutrition in:

... classes for parents and the recipes in the magazine.
It was a friend of mine that was very health conscious like I said with the fresh vegetables, she is the person that started me on the healthy vegetables and eating the fruit and how to make different snacks; so actually it came from a friend.

Of note, the most frequent response of who was the most trusted source of information was the physician. However, some participants expressed that physicians often did not provide any guidance related to nutrition and their overweight children, suggesting the physician visit is a missed opportunity for this population. Although they stated they would believe the doctor,

He doesn't say anything about that. I take my little fat girl to the doctor and nothing. No. Well, they say we should read and there are things you can take, but no they do not recommend anything for the nutrition issue.

Objective 2: learning about parents' barriers to and promoters for establishing bealthy eating habits for children and families

Participants were first asked what healthy eating meant to them. From this discussion participants were asked if they thought their diet included enough healthy options. Participants expressed they wanted their families to consume more healthy foods. This led to a discussion of what were the major barriers in their lives to buying and consuming healthier food. The most often mentioned barrier was cost, followed by child's food preferences for unhealthy foods compared with healthy foods, and lack of time for food preparation leading to purchasing meals at fast-food establishments:

Healthy food? It costs more. Like if you want to get nice quality food, if you want to shop for healthy foods, it's almost not possible for us, being low-income families. But we're trying our best to buy our best.

In addition, many parents mentioned their children do not like the taste of 'healthy' food and therefore won't eat it. Thus, parents expressed difficulty in promoting healthy eating and convincing their child to eat healthy foods. In contrast, parents stated their children like 'junk food'. Child's food preferences are thus a predictor to eating behaviour. When children prefer fast-food establishments it is made even more challenging for the parents; they described the constant struggle with their children between healthy food and fast food since fast-food establishments are everywhere:

My child has a tantrum if he sees any fast food place and that makes it really hard.

She doesn't like potatoes, broccoli, and carrots. I have to come up with inventions for her to eat them.

I am having a battle with him and fruit and trying not to put the chips in there. 
Lack of time was identified as the other major barrier to eating healthy and, as a consequence, 'fast food' was a convenient option.

\section{Objective 3: learning about parents' interest in participating} in nutrition interventions

The parents expressed a willingness to participate in group nutrition education. They were most interested in participating in interactive activities rather than just learning specific facts. Specifically, they wanted to learn how to cook and how to cook healthier foods - especially how to substitute/modify recipes so that they are healthier and their children will find the modified food tasty. They also wanted to learn how to teach their children how to be healthy and make nutritious choices:

Practice what you're learning. If you don't practice, how will you learn it?

Yes! Someone just showing how.

A cooking demonstration where everybody gets to have a taste.

In addition, parents felt that written materials in the form of pamphlets or brochures would be an ideal method to provide information, similar to how they were learning nutrition information already. A few parents said they would appreciate receiving a DVD, CD or video with class information:

Apart from the demonstrations, they could give us books or magazines. Something like that.

As for topics to be covered in the nutrition education class, the most common responses were basic information including why it's important to eat healthily, cooking healthily/making healthy substitutions, how to encourage children to eat healthier, portion sizes, the role of different vitamins and nutrients, label reading to identify what ingredients were in various foods, and ideas for exercise.

They want labels that would include what was in vegetables so they know which ones have more iron' and also labels that say 'it's good for your bones, brain and kidneys':

How to cook with products that are, you know, more accessible to us.

Like we're used to using oil, something that can be used doing the same thing, but that is not oil.

I would like to learn how to read the labels because there are times that we read the labels with the nutritional value. And sometimes it says so much that we don't know what calorie means.

Participants were asked questions regarding the logistics of attending nutrition education classes, such as the time of day that would be most convenient, preferable location and who should be invited to participate.
The major theme of including the family in the nutrition education was expressed and the times for the classes reflected this wish.

There was not a clear best time of day to attend nutrition education classes for the focus group participants. Most of the participants indicated either before or after school, when parents are dropping off or picking up their children, would be best. Some indicated during school hours would also be a possibility. There was no preference regarding what day of the week the nutrition education classes should be offered. Regarding length of the class, most participants felt 1.5 to $2 \mathrm{~h}$ one time per month would be acceptable. Overwhelmingly, parents felt the school was the ideal location for the nutrition education classes.

Participants liked the concept of a nutrition class and thought it would be an effective way to improve nutrition for the whole family. They indicated the entire family including fathers and children should be included in the nutrition programmes when possible.

To entice parents to attend the classes, food vouchers or gift certificates and/or other types of prizes including food and kitchen items were identified as attractive incentives for participation. Additionally, parents felt providing recipes would be an ideal incentive for parents who attended the nutrition education classes:

If you say there is going to be a recipe given, we are serving a meal and you are going to have the opportunity to be on hands preparing it. I think a lot of people would come.

The first thing they ask is if we're going to have prizes or give out food.

Well you have to come because of the children because it's their future.

I would be happy with recipes.

The incentives and basically to learn how to be more nutrition.

\section{Discussion}

Focus group interviews were conducted with parents of children from the LAUSD to gain a better understanding about parents': (i) knowledge regarding healthy foods, factors associated with food purchasing and preparation, and current nutrition education resources; (ii) barriers to and promoters for establishing healthy eating habits for children and families; and (iii) interest in participating in nutrition interventions. Two major themes emerge from these focus groups: (i) the balance of the pluses and minuses determining the decisions on healthy eating; and (ii) the topic of the child and family and its importance not only in motivating parents in making healthy choices for the health of the family, but also in including as many 
of the family decision makers as possible in nutrition education efforts. The discussion below is organized to follow the three objectives for the study. While during the focus group discussions the researchers asked questions focused specifically on the objectives, the participants had similar responses related to the first and second objectives.

Objective 1, to learn more specifically about LAUSD parents' knowledge regarding healthy foods, factors associated with food purchasing and preparation, and current nutrition education resources, was met. Parents in the study sample had a basic knowledge about what foods are healthy and expressed an interest and concern about nutrition and its relationship to health. They consider their children's health when shopping and preparing foods for their families. They try to choose nutritious foods and seek ways to prepare these foods in a more healthful manner for the family. Other researchers describe this theme of making choices due to the health of the family ${ }^{(11,12)}$. Studies have found parents not to be receptive to interventions aimed at specifically changing dietary behaviour, but are more motivated to engage in healthy behaviours and positive health beliefs within the family setting ${ }^{(11,12)}$. Hart et al. suggest parent-targeted strategies should emphasize: (i) awareness-raising interventions such as promoting the acceptance of healthy foods and behaviours through repeated exposure techniques; (ii) encouraging family responsibility for diet and exercise rather than just providing parents with 'specific guidelines' to follow; and (iii) promoting dietary variety to tackle the myth of healthy eating as restrictive, expensive and unattainable ${ }^{(11)}$. Parents' knowledge of healthy foods and their child's food preferences related to healthy foods influenced food purchasing and preparation and parents balanced this with the barriers to healthy eating.

Parents reported multiple sources of nutrition education, suggesting multiple opportunities to reach parents. They reported receiving most of their nutrition education through various media sources (e.g. TV, radio, Internet, newspapers, magazines and books). Many parents reported TV was especially useful for learning new recipes and new ways to prepare foods that are healthier. Mothers and physicians were also identified as important sources of nutrition information. Unfortunately, parents in the study stated their physicians did not provide them with nutrition information. Other researchers have reported this finding, although parents desire such information from their physicians ${ }^{(12)}$. Future interventions should consider providing parents with the skills necessary to communicate with physicians regarding questions and concerns related to their children's health and behaviour.

Objective 2, to learn more specifically about LAUSD parents' barriers to and promoters for establishing healthy eating habits for children and families, was met. The most common barriers to eating healthy foods were cost, difficulty in getting their children to eat healthier foods and easy access to fast food. These findings are similar to those in previous studies ${ }^{(6,11,13,30)}$. For example, work by Goh et al. showed parents reported easy access to unhealthy food contributed significantly to unhealthy food choices, and often chose fast food for family meals because of ease and low cost ${ }^{(13)}$. Hesketh et al. also found that parents reported increasing numbers of fast-food restaurants as obstacles to healthy eating ${ }^{(30)}$. Interventions could include teaching parents how to increase healthy food intake, prepare healthy foods on a limited budget, provide recipes for tasty snacks and dinner entrées that are quick and easy to make as alternatives to fast food, and provide parents with strategies to limit exposure to and consumption of unhealthy foods ${ }^{(6)}$. While parents identified these barriers, they also weighed the importance of their child's health and food preferences against these barriers and often the child's health and food preferences helped to overcome the barrier such as cost. The weighing of the pros and cons for decision making related to the health of the child was a major theme during the focus group discussions. The knowledge of what was healthy for their children was clearly a promoter for good health outweighing barriers such as cost.

Objective 3, to learn more specifically about LAUSD parents' interest in participating in nutrition interventions, was met and additional information on how to implement the classes was elicited. Parents in our study were clearly open to learning about nutrition, with half reporting participating in some nutrition class and the vast majority (90\%) indicating they would be willing to take a class. They expressed a desire for nutrition classes in a school setting, saying it would be an effective way to improve nutrition for the whole family. The theme of including the whole family recurred multiple times in the focus group discussions, especially when discussing nutrition classes. Expert work groups recommend exactly this strategy of engaging the whole family in interventions that treat and prevent childhood obesity ${ }^{(4)}$. Supporting parents in making healthy food choices for themselves is one form of family engagement and could be an important strategy in improving children's diet.

There were limitations to our study. First, we chose focus group interviews as our method to explore barriers to and promoters of health eating. This methodology facilitates in-depth discussion of individual perspectives within the context of a larger group but may overrepresent specific participant contributions; therefore, aggregate group data may not reflect equally the specific concerns of every group participant. Also, convenience sampling and selection bias (mostly Hispanic/Latino women) limit the ability to generalize our results to all LAUSD parents. Furthermore, due to time restrictions we did not obtain detailed demographic information about the focus group participants and therefore do not have details about size of household, number of children in the family and other demographics. 
Parenting behaviours have been identified as an important factor in shaping children's dietary practices $^{(3,4,8,10,31)}$. In order to meet the Dietary Guidelines for Americans (2005) and reverse the trend of children who are increasingly overweight or obese, parents should be a key focus in nutrition interventions to promote healthy eating among children ${ }^{(4)}$. While limited time, accessibility and preference for unhealthy foods and cost are challenging barriers to overcome, participants in these focus groups offer insight into how they balance this with the desire to buy and prepare healthy foods their child likes, their knowledge of healthy foods and how to prepare them, and their access to multiple sources of nutrition information. Furthermore, the focus group findings are a promising indication parents would be receptive to interventions aimed at encouraging healthful eating behaviours for their children and family. The present study adds new information to the small body of existing literature on low-income predominantly Latino parents': (i) knowledge regarding healthy foods, factors associated with food purchasing and preparation, and current nutrition education resources; (ii) barriers to and promoters for establishing healthy eating habits for children and families; and (iii) interest in participating in nutrition interventions. Focusing on the health of the family, engaging the whole family in these discussions and educational experiences, and discussing and presenting the pros and cons of choices related to nutrition and physical activity could help support families in a healthier lifestyle. The results of our focus group study led to the development and implementation of a school-based parent nutrition education programme consisting of five 90-min workshops during the 2008/2009 academic year. Findings from that study are currently in press and suggest that the school site may provide an ideal setting to intervene with parents on their knowledge about food and nutrition topics ${ }^{(32)}$.

\section{Acknowledgements}

The study was funded was through a subcontract from the Network for a Healthy California-LAUSD, which in turn is funded by the USDA. There are no conflicts of interest for any of the authors. Author contributions were as follows. W.S., lead author of paper and co-Principal Investigator of the project: formulated questions for the focus group and led on the analysis of the data. M.P., Principal Investigator of the research project: helped design questions for the focus group and in analysis and write-up of the findings. J.K.: helped write the manuscript and formulate the discussion of the findings. J.T.E., lead statistician: helped with analysis of the data and write-up of the findings. C.T.: helped formulate questions for the focus group and in analysis of the findings and write-up. C.N., co-Principal Investigator of the project: helped formulate questions for the focus group and in analysis and write-up of the findings. We thank staff at the Network for a Healthier CaliforniaLAUSD; Soustana Haftoglou, MPH who helped facilitate the focus groups; LAUSD parents who participated in the focus groups; and the LAUSD administrators at the schools where the focus groups were held for graciously opening their schools to us.

\section{References}

1. Kroller K \& Warschburger P (2008) Associations between maternal feeding style and food intake of children with a higher risk for overweight. Appetite 51, 166-172.

2. Benton D (2004) Role of parents in the determination of the food preferences of children and development of obesity. Int J Obes Relat Metab Disord 28, 858-869.

3. Elder JP, Arredondo EM \& Campbell N (2010) Individual, family, and community environmental correlates of obesity in Latino elementary school children. $J$ Sch Health 80, 20-29.

4. Koplan JP, Liverman CT \& Kraak VI (2005) Preventing Childhood Obesity: Health In Balance. Washington, DC: Institute of Medicine.

5. Demory-Luce D, Morales M, Nicklas T et al. (2004) Changes in food group consumption patterns from childhood to young adulthood: the Bogalusa Heart Study. J Am Diet Assoc 104, 1684-1691.

6. Power TG, Bindler RC, Goetz S et al. (2010) Obesity prevention in early adolescence: student, parent, and teacher views. J Sch Health 80, 13-19.

7. Fisher JO \& Birch LL (2002) Eating in the absence of hunger and overweight in girls from 5 to 7 years of age. Am J Clin Nutr 76, 226-231.

8. Golan M \& Crow S (2004) Parents are key players in the prevention and treatment of weight-related problems. Nutr Rev 62, 39-50.

9. Fulkerson JA, Story M, Neumark-Sztainer D et al. (2008) Family meals: perceptions of benefits and challenges among parents of 8- to 10-year-old children. J Am Diet Assoc 108, 706-709.

10. Nicklas TA, Baranowski T, Cullen KW et al. (2001) Eating patterns, dietary quality and obesity. J Am Coll Nutr 20, 599-608.

11. Hart KH, Herriot A, Bishop JA et al. (2003) Promoting healthy diet and exercise patterns amongst primary school children: a qualitative investigation of parental perspectives. J Hum Nutr Diet 16, 89-96.

12. McKee DM, Maher S, Deen D et al. (2010) Counseling to prevent obesity among preschool children: acceptability of a pilot urban primary care intervention. Ann Fam Med 8, 249-255.

13. Ciampa PJ, Kumar D, Barkin SL et al. (2010) Interventions aimed at decreasing obesity in children younger than 2 years: a systematic review. Arch Pediatr Adolesc Med 164, 1098-1104.

14. Goh YY, Bogart LM, Sipple-Asher BK et al. (2009) Using community-based participatory research to identify potential interventions to overcome barriers to adolescents' healthy eating and physical activity. J Behav Med 32, 491-502.

15. Pérez-Rodrigo C, Klepp KI, Yngve A et al. (2001) The school setting: an opportunity for the implementation of dietary guidelines. Public Health Nutr 4, 717-724.

16. Anderson AS, Porteous LEG, Foster E et al. (2005) The impact of a school-based nutrition education intervention on dietary intake and cognitive and attitudinal variables relating to fruits and vegetables. Public Health Nutr 8, 650-656. 
17. Baranowski T, Davis M, Resnicow K et al. (2000) Gimme 5 fruit, juice, and vegetables for fun and health: outcome evaluation. Health Educ Behav 27, 96-111.

18. Winslow EB, Bonds D, Wolchik S et al. (2009) Predictors of enrollment and retention in a preventive parenting intervention for divorced families. J Prim Prev 30, 151-172.

19. Flegal KM, Carroll MD, Curtin LR et al. (2010) Prevalence of high body mass index in US children and adolescents, 2007-2008. JAMA 303, 242-249.

20. Hedley AA, Ogden CL, Johnson CL et al. (2004) Prevalence of overweight and obesity among US children, adolescents, and adults, 1999-2002. JAMA 291, 2847-2850.

21. Slusser W, Cumberland WG, Browdy BL et al. (2005) Overweight in urban, low-income African American and Hispanic children attending Los Angeles elementary schools: research stimulating action. Public Health Nutr 8, 141-148.

22. Los Angeles County Department of Public Health (2008) Childhood Obesity: Tipping the Balance Toward Healthy Active Children, LA bealth. Los Angeles, CA: LA County Department of Public Health.

23. The City Project (2007) Helping children move more, eat well, stay healthy, and do their best in schools and in life. http://www.cityprojectca.org/ourwork/schools.html (accessed June 2010).

24. Ogden CL, Flegal KM, Carroll MD et al. (2002) Prevalence and trends in overweight among US children and adolescents, 1999-2000. JAMA 288, 1728-1732.
25. Ogden CL, Carroll MD, Curtin LR et al. (2008) High body mass index for age among US children and adolescents, 2003-2006. JAMA 299, 2401-2405.

26. Ogden CL, Carroll MD, Curtin LR et al. (2010) Prevalence of high body mass index in US children and adolescents, 2007-2008. JAMA 303, 242-249.

27. Summer L, Briggs R \& Bell L (1997) Needs Assessment Resource Manual: A Guide for the State Nutrition Education Networks. Washington, DC: Health Systems Inc.

28. Janz N, Champion V \& Strecher V (2002) The health belief model. In Health Behavior and Health Education; Theory, Research and Practice, 3rd ed, pp. 45-66. [K Glanz, B Rimer and F Lewis, editors]. San Francisco, CA: Jossey-Bass.

29. Glaser BG \& Strauss AL (1967) The Discovery of Grounded Theory: Strategies for Qualitative Research. Chicago, IL: Aldine Publishing Company.

30. Hesketh K, Waters E, Green J et al. (2005) Healthy eating, activity and obesity prevention: a qualitative study of parent and child perceptions in Australia. Health Promot Int 20, 19-26.

31. Dietz WH \& Gortmaker SL (2001) Preventing obesity in children and adolescents. Annu Rev Public Health 22, 337-353.

32. Prelip M, Thai Chan Le, Erausquin JT et al. (2011) Improving low-income parents' fruit and vegetable intake and their potential to impact children's nutrition. Health Educ (In the Press). 